\title{
Outlook for Producer Economies
}

\author{
Ali Al-Saffar
}

\section{Introduction: Risks to Producer Economies- Current Problems and Emerging Pressures}

The oil price cycle of the last decade has exposed once more some of the enduring structural economic weaknesses in "producer economies", those countries for whom oil and gas revenue constitutes a significant proportion of exports and fiscal revenue. ${ }^{1}$ As the most prominent producing region in the world, the impact of the change in oil prices has been particularly acute in the Middle East, where average net incomes from oil and gas fell by $40 \%$ in 2015-2018 compared to their highs in 2010-2014 (International Energy Agency 2018). The public debate on the need to

The contents of this chapter are based on the Outlook for Producer Economies, published by the International Energy Agency in October 2018. Ali Al-Saffar was the lead author.

${ }^{1}$ For the purpose of this chapter, it is assumed that producer economies are those countries in which oil and gas exports make up at least one-third of total goods exports, and where revenues from oil and gas contribute to at least one-third of total fiscal revenue.
A. Al-Saffar $(\bowtie)$
International Energy Agency, Paris, France
e-mail: Ali.AL-SAFFAR@iea.org
(C) The Author(s) 2021
G. Luciani, T. Moerenhout (eds.), When Can Oil Economies Be
Deemed Sustainable?, The Political Economy of the Middle East, https://doi.org/10.1007/978-981-15-5728-6_4 
diversify oil- and gas-dependent economies has once again gathered steam, with several countries announcing ambitious reform programmes aimed in large part at reducing their dependence on hydrocarbons revenue.

In the past, the imperative to reform has waxed and waned, following closely the oil price cycle, but the combination of pressures from shale oil in the United States, which accounted for 7 in every 10 incremental barrels since 2008, and the long-term uncertainty over demand for oil and gas are intensifying the imperatives for change (ibid.). Fundamental changes to the development model in resource-rich countries look unavoidable. This chapter will enumerate how pressures on producers across the Middle East could evolve, using the results of the International Energy Agency's New Policies and Sustainable Development Scenarios. While acknowledging that the reform agenda will necessarily be much broader than just energy, it will propose ways in which the energy sector can be leveraged to help promote a more balanced economy.

\section{How Do the Economic Pressures in Producer Economies Evolve GoIng Forward?}

There are multiple uncertainties affecting the outlook for hydrocarbons and the revenue flows that sustain producer economies, not only because of fluctuating prices, but also because of questions concerning long-term demand. How the economic pressures on producer economies evolve in the future depends largely on what the energy sector looks like going forward. To get a sense of the range of possibilities, we will examine two distinct trajectories.

The New Policies Scenario provides a measured assessment of where today's policy frameworks, and policies that have been announced but not yet implemented, together with the continued evolution of known technologies, could take the energy sector. In this scenario, equilibrium prices for oil and natural gas (in the context of rising global demand for both commodities) rise gradually from today's levels. The pace of oil demand growth slows markedly, but there is no peak in global consumption, and demand is expected to reach 106 million barrels per day (mb/d) by 2040 . Demand for natural gas increases strongly and accounts for a quarter of global primary energy demand by 2040 .

The combination of continually growing oil demand and the attendant robust prices may at first appear to offer a relatively benign outlook for 
major producers - by the late 2020s, annual net income from oil and gas is higher for all Middle East producers than it was in 2010-2017 (Fig. 4.1). But several important factors need to be considered that would suggest that even here, the incentive to diversify oil-dependent economies remains strong.

The first is that the short- and medium-term market dynamics differ considerably from the long-term ones. The majority of the growth in oil production until 2025 continues to come from countries outside of the Middle East, particularly from the United States. It is only after 2025, once the US tight oil plateaus and then starts to fall back, that the world again becomes more reliant on the major conventional oil resourceholders to balance the market. This is why, in most cases, the pick-up in oil net income takes place only in the latter years. These latter years are the ones where there is the most uncertainty about the outlook for demand.

Secondly, while the broad pattern may show absolute levels of income growth, this masks the volatility imposed by price cycles, which, in the absence of new policy tools in many producers, could translate into uncertain fiscal spending and unpredictable economic growth.

Lastly, it is crucial to incorporate the impact of population growth. For sizeable producers with relatively small populations (e.g., the United Arab Emirates, Kuwait and Qatar), this is less of a concern. However, in the region's two largest producers Iraq $(+28$ million increase in population anticipated by 2040) and Saudi Arabia (+10 million), population growth

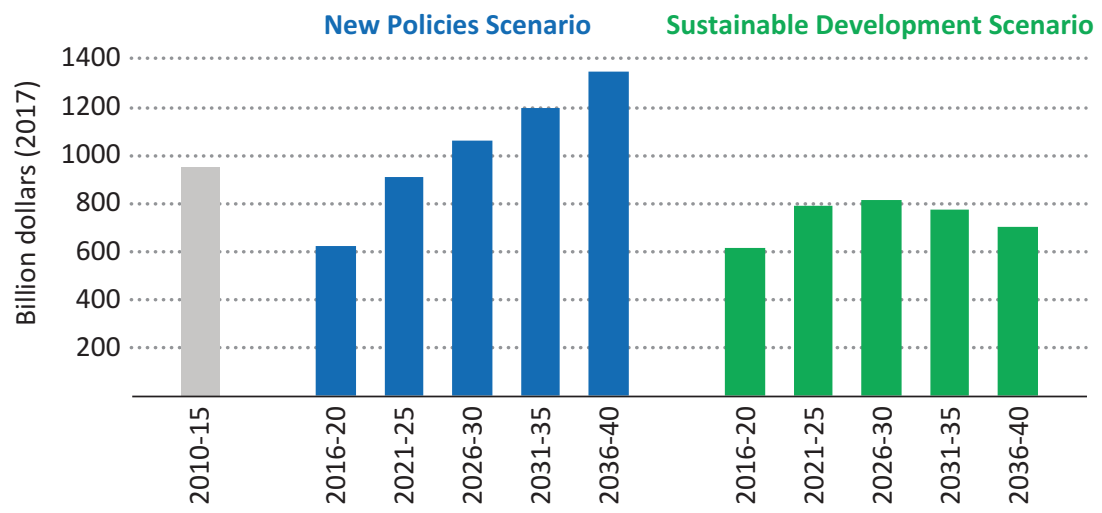

Fig. 4.1 Average annual net income from oil and gas in Middle East producers. (Source: International Energy Agency) 
has significant implications for net income from oil and gas when calculated on a per-capita basis. This indicator will decline in Saudi Arabia over the period until 2025 and increase only modestly overall until 2040, despite a large increase in total net income (Fig. 4.2).

Population growth also has implications for patterns of employment. If we assume that the public sector employs the same proportion of the labour force in 2030 as it does today, Iraq's public sector wage bill would increase by almost $150 \%$, even without any real increase in average salaries, reaching over $\$ 70$ billion in 2030 (equivalent to $40 \%$ of its net income from oil and gas in 2030). The public sector wage bill in Saudi Arabia would increase even more, reaching almost $\$ 200$ billion (or $60 \%$ of its net income from oil and gas in 2030). Pressure for reform in some key producer economies remains high, even in a world where demand for oil continues to increase and oil prices remain robust.

The possibility that the energy sector moves in another direction is examined in the Sustainable Development Scenario. This scenario starts from some key energy-related components of the Sustainable Development Goals ${ }^{2}$ and then works back to the present to see how

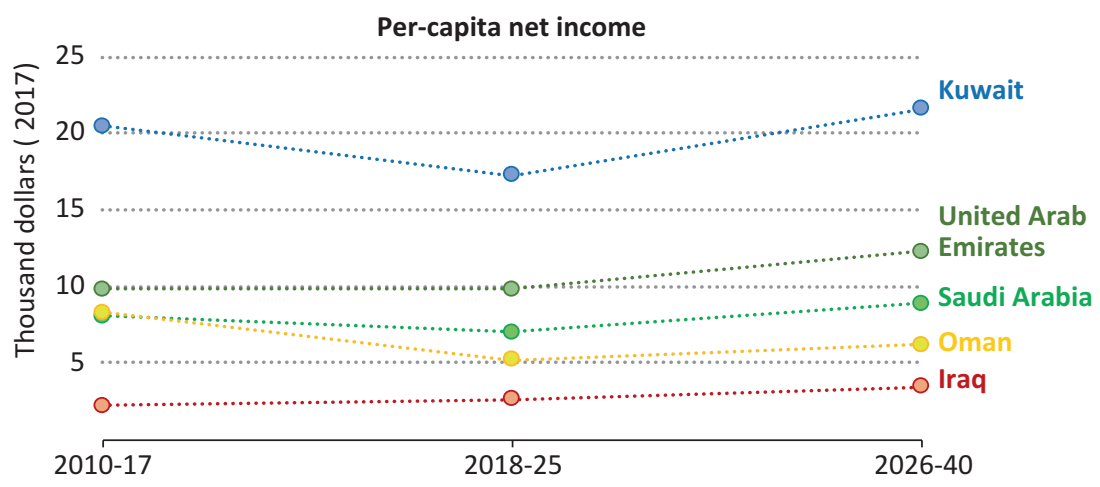

Fig. 4.2 Total net income from oil and gas in the New Policies Scenario. (Source: International Energy Agency)

\footnotetext{
${ }^{2}$ These goals include achieving universal access to modern energy by 2030 , reducing dramatically the premature deaths due to energy-related air pollution and delivering on the Paris Agreement - this scenario is therefore fully aligned with the Agreement's goal of limiting the increase in the global average temperature to "well below $2{ }^{\circ} \mathrm{C}$ ".
} 
they might be achieved. It sets out the major changes that would be required to deliver these goals simultaneously. As such, it incorporates not only price effects for oil and gas, but also a major change in the volumes demanded. In this scenario, oil demand peaks in the near term and will then decline to around $70 \mathrm{mb} / \mathrm{d}$ by 2040 , while natural gas consumption rises by only one-quarter the amount projected in the New Policies Scenario.

An energy sector that is set on a trajectory that complies with the Paris Climate Agreement looks significantly different to the one that prevails today, and indeed from the New Policies Scenario discussed earlier. For producer economies, the effects of a smaller market for oil are compounded by lower prices for it, causing cumulative net incomes across the Middle East to fall until 2040 by over one-quarter relative to their levels in the New Policies Scenario. In such a scenario, constrained government revenues make it harder to manage immediate budgetary requirements while simultaneously complicating the task of making changes to diversify the economy (Fig. 4.3).

Total net income

Saudi Arabia

(-26\%)

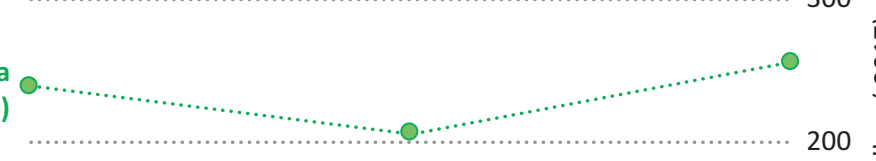

United Arab

Emirates (-29\%)

Iraq (-30\%)

$8:$

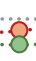

Kuwait (-30\%)

Oman (-28\%)

2010-17

$2018-25$

$2026-40$

Fig. 4.3 Total net income from oil and gas in the Sustainable Development Scenario. Note: The change in average annual net income until 2040, relative to the New Policies Scenario, is shown in brackets. (Source: International Energy Agency) 


\section{The Macro-Economic IMPACT of THE Two Scenarios}

Beyond the decrease in net income, what could lower oil prices mean for the economic outlook in producer economies?

To help answer this question, we coupled the results of the International Energy Agency's World Energy Model with the Organisation of Economic Co-operation and Development's (OECD) computable general equilibrium model, ENV-LINKAGES, to generate results for the Middle East. This modelling does not assume that major structural economic changes take place among the world's major hydrocarbon producers, but instead assumes a degree of continuity with the past, in which diversification efforts have made steady, rather than transformative, progress.

The results of this economic modelling show that as export revenues decline in the period until 2025 in a lower oil price environment, the trade balance falls into deficit for the Middle East as a whole and stays in deficit through to 2040. For countries that have a floating exchange rate, the resulting currency depreciation makes imports ever more expensive. For countries that have pegged regimes, such as the Gulf producers and Iraq, maintaining the link becomes an increasingly difficult and expensive proposition. Furthermore, reduced revenues impinge on the ability of countries to pursue expansionary fiscal policies to stimulate growth. This hits all sectors of the economy, with the business services and public sector output each around 20\% smaller in 2040 than in the New Policies Scenario, and construction output reduced by more than $15 \%$. This has implications for jobs in the Middle East: there will be 8 million fewer jobs in 2040 than in the New Policies Scenario.

The net impact of these effects is that wider economic output is severely curtailed compared with the New Policies Scenario. In the Middle East alone, the cumulative economic losses between 2018 and 2040 amount to $\$ 11$ trillion, five times the current GDP of the region, and the economy is one-fifth smaller by 2040 than in the New Policies Scenario. This has a clear impact even at the household level where the average person in the Middle East has $\$ 1500$ less disposable income per year than they would in the New Policies Scenario to 2040. 


\section{The Future Role of a Competitive ENERGy Sector}

The reform agenda for producers looking to diversify their economies and make them more resilient to commodity price movements is, fundamentally, much broader than energy. However, the overall reform efforts could benefit from a well-functioning energy sector. If channelled efficiently, it could provide a platform, both in terms of revenue and comparative advantage, for achieving broader social and economic objectives. We identify six key areas where producer economies can leverage their energy sectors to provide long-term advantage and increase their resilience to a range of future market and policy possibilities.

\subsection{Capturing More Value from Hydrocarbons}

Across the Middle East, producers have already made significant efforts to move downstream in an effort to capture additional value from hydrocarbons resources. The Middle East currently accounts for around 10\% of global refinery runs, and this share is set to increase as several large-scale projects, such as the Jubail, Yanbu and the Jizan complex in Saudi Arabia, are already under construction across the region. Countries are not limiting this increase in capacity to their home territories, and several are pursuing growing markets, notably in Asia. Saudi Aramco recently reached agreements to invest in refineries in China, India, Indonesia, Malaysia and the United States, while the Kuwait Petroleum Corporation is looking at investments in India's Bina Refinery.

There are several motivations behind this downstream drive, including a wish to extract more value from the oil the region produces and to secure outlets for crude exports. The expansion increases revenues for each barrel produced, and thereby also risks increasing dependency on oil revenue. However, downstream earnings typically move in a different direction from upstream earnings - they tend to be higher when crude oil prices are low, and vice versa-so they also provide a hedge against lower oil prices.

Producers across the Middle East are also pursuing large investments in petrochemicals complexes. Beyond the attraction of potentially higher and more resilient margins, the likelihood of a robust outlook for petrochemicals products in all scenarios means that these offer a degree of hedging against the possibility of a contraction of oil demand as a result of a rapid 
uptake of electric vehicles or higher levels of efficiency improvements in a transitioning energy world. Indeed, even though there is growing attention on reducing single-use plastics and increasing plastic recycling, especially in advanced economies, the impact of these trends is more than offset by a surging demand in developing economies and the increasing use of plastics in place of other materials such as wood and metal. As such, oil demand for petrochemicals is expected to increase by around $5 \mathrm{mb} / \mathrm{d}$, accounting for the largest share in incremental oil demand growth until 2040.

Middle East chemical production is expected to double between today and 2040-allowing the region's share in global chemical production to increase by four percentage points, reaching $17 \%$ by 2040 on the back of feedstock cost advantage and the high level of efficiency of newly built facilities. A corollary of this increase in downstream activity is that out of a $6.5 \mathrm{mb} / \mathrm{d}$ incremental increase in oil supply until 2040 from the region, only $800 \mathrm{~kb} / \mathrm{d}$ is exported as crude (with additional $2.1 \mathrm{mb} / \mathrm{d}$ passing through refineries, and $3.6 \mathrm{mb} / \mathrm{d}$ being used in petrochemicals production).

\subsection{Using Natural Gas Strategically in Support of Diversification Goals}

In several prominent oil producers in the Middle East, natural gas has been considered as being a sometimes-convenient by-product of oil extraction. Rising consumption, particularly in power generation, and the limited availability of associated gas (with the exception of Qatar) now require that gas be sought and produced as a commodity in its own right, and often imported. This requires a reassessment of pricing policies to incentivise upstream activity, as well as a review of the priority sectors for gas consumption.

There is also a pressing case for a fundamental rethink of the strategic importance of natural gas, including where it is likely to bring the best value within the energy system, especially in countries where there are strains on the gas balance. In many cases, gas can bring value by displacing oil in domestic energy use, especially where oil is combusted to generate electricity. But there is a strong economic case across the Middle East for faster deployment of solar PV to displace gas as well as oil in power generation, which would augment gas availability for use in value-added industries. 
The potential significance of natural gas is broader than the direct incomes that it can bring; it can underpin an industrial strategy in a way that oil cannot, and in this sense can be an important conduit to economic diversification. At present, most industrial applications of gas are capitalbut not labour-intensive. For example, the Qatar Petrochemical Company generates more than $\$ 1$ billion in annual revenues, but employs just 1000 people. These large industrial complexes, however, can act as anchor consumers to help underwrite large infrastructure investments that bring benefits to smaller industrial consumers, supporting the emergence of lighter manufacturing and small and medium enterprises, which thereby contribute to economic diversification and job creation. Indeed, in the projections of the International Energy Agency's (IEA)s World Energy Outlook, industry is a key driver of natural gas consumption growth in the Middle East, increasing by $65 \mathrm{bcm}$ until 2040, reaching $170 \mathrm{bcm}$.

\subsection{Tapping the Large, Underutilised Potential of Renewables}

The anticipated growth in demand for electricity in a number of producer economies raises questions about the economic viability of the current mode of electricity supply. Across the Middle East, for example, a 5.7\% per year increase in electricity demand has translated to a doubling in the region's oil consumption for power generation over the last 20 years, reaching around $1.8 \mathrm{mb} / \mathrm{d}$ in 2017 . This diverts oil away from exports towards inefficient domestic consumption and incurs a significant opportunity cost-especially significant in periods when global spare production capacity look thin.

At present, peaking capacity in many parts of the Middle East is provided by oil-fired plants, often burning crude oil directly or using heavy fuel oil. In Saudi Arabia, for example, the daily load curve in summer reaches almost twice its peak in winter months because of air conditioning use. This means that 20-25 gigawatts out of a total of 88 gigawatts of capacity are used only for around half the year. These are mostly oil-fired plants, and they increase daily liquids burn by as much as $500 \mathrm{~kb} / \mathrm{d}$ in peak summer periods relative to winter months. In the future, without a significant improvement in efficiency over time, and considering the large anticipated increase in the use of air conditioners across the Middle East (demand for space cooling alone could skyrocket from 135 terawatt-hours (TWh) today to over 300 TWh in 2040), the peak will grow significantly, 
giving a measure of the imperative for a more efficient electricity system going forward.

Solar resources are abundant and are ideally suited to meeting this peak (daily demand for cooling peaks in the early afternoon, matching the normal peak in solar PV output). At present, this potential is almost entirely untapped, with the $1.2 \mathrm{GW}$ of solar capacity making up less than $0.5 \%$ of total generation capacity in the Middle East (compared to over $90 \mathrm{GW}$ of oil-fired capacity). But fast-falling costs for solar PV mean that, even if oil were priced for generation at $\$ 40 /$ barrel, unsubsidised solar would be displacing it quickly on a cost competitive basis (Fig. 4.4).

Although the economic case for renewable power is compelling, reaching deployment levels that reflect this will depend on removing barriers to their uptake. However, at current levels of deployment, concerns about the impact of variable renewables on grid stability in the Middle East are limited, although care will be needed to ensure that network planning matches plans for new utility-scale renewable projects. Most GCC countries in particular have generation fleets that are flexible enough already to enable a much higher penetration of renewables, and the rise in electricity demand for desalination could provide a further synergy for renewables, providing the option of being used as a demand response facility, helping to ensure an outlet during periods of excess electricity production.

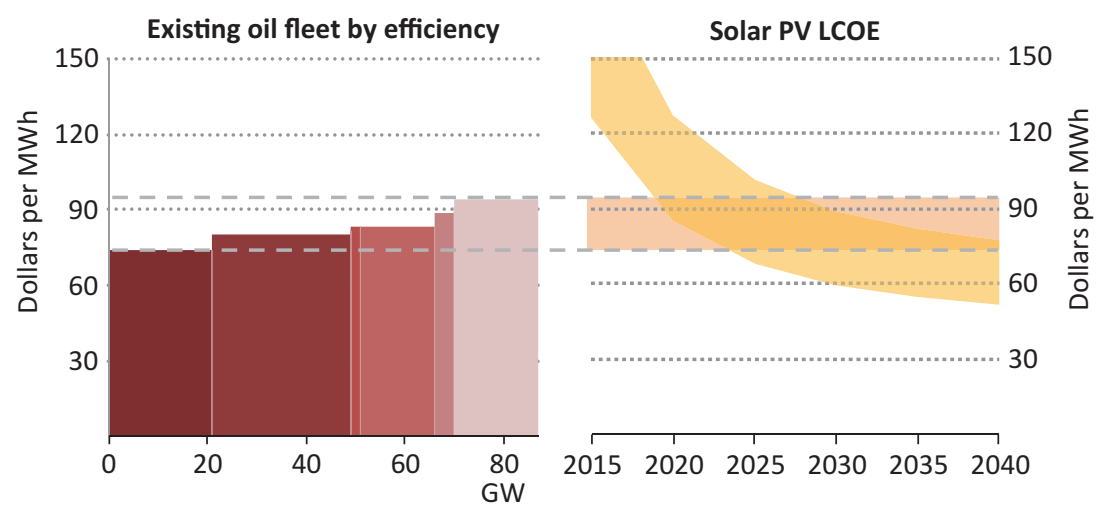

Fig. 4.4 Levelised cost for solar PV compared with existing oil-fired generation at $\$ 40$ per barrel oil price. (Source: International Energy Agency) 


\subsection{Phasing Out Subsidised Use of Energy to Improve Its Efficiency}

According to estimates by the International Energy Agency, fossil-fuel consumption subsidies totalled around \$105 billion across the Middle East in 2017 (Fig. 4.5). Prices for oil products and natural gas in most producer economies are well below the value that could be obtained for these commodities on the international market, even after transportation costs are taken into account. Eleven major producer economies in the world-Bahrain, Iran, Iraq, Kuwait, Nigeria, Oman, Qatar, Russia, Saudi Arabia, UAE and Venezuela-account for around half of the International Energy Agency estimate for worldwide fossil fuel consumption subsidies, which, in most cases, represent foregone revenue rather than actual budgetary payments.

Artificially cheap energy encourages wasteful consumption-primary energy demand in the Middle East has grown at 4.4\% per year since 2000, a rate that is more than double the world average. Among other things, this has meant that two in every five new barrels of oil production have been consumed domestically in this time. Economies across the region are

50

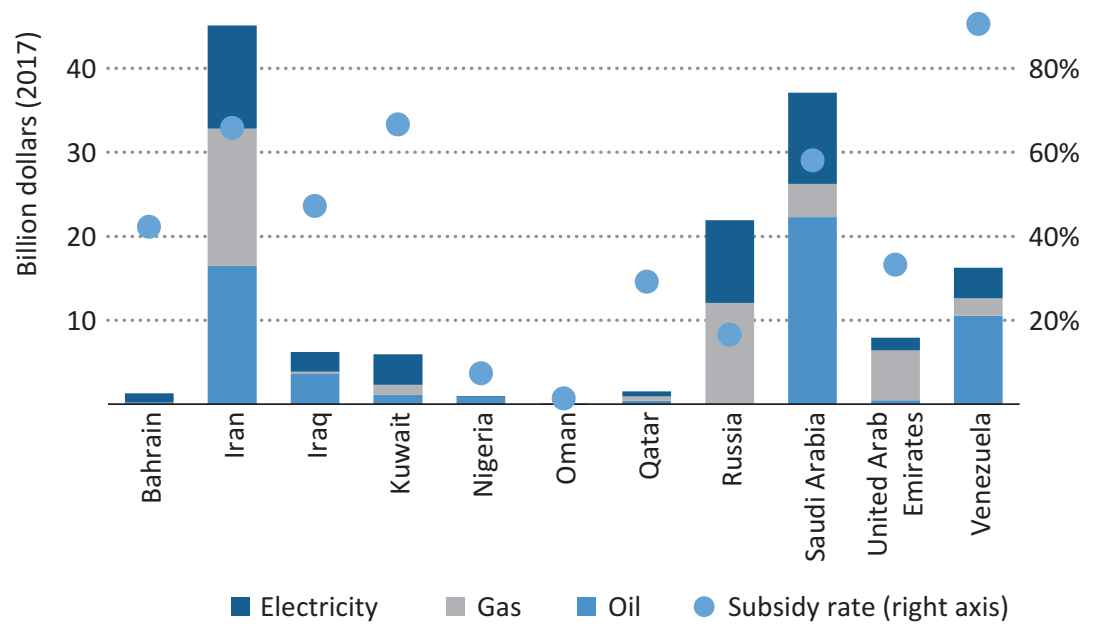

Fig. 4.5 Estimated value of fossil fuel subsidies in selected producer economies, 2017. (Source: International Energy Agency) 
now among the most energy-intensive in the world-the United Arab Emirates, the least intensive in the region, requires 10\% more energy to generate a dollar of economic output than the world average.

Beyond the fiscal burden and their impact on consumption, subsidies also distort broader investment incentives across the energy sector. Low natural gas prices, for example, have reduced the incentive for private companies to invest in new exploration and production projects in parts of the Middle East. As well as accommodating for the fact that low-cost energy is deeply embedded in the social contract in many producer economies, successful reform must also reconcile the need to reform prices with the imperative of sustaining or even enhancing industrial competitiveness. Across the Middle East, even without subsidies, most oil and gas producers would still have a comparative advantage in energy, since a low production cost base can provide a stable low domestic price.

The implications of pricing reform for energy consumers can be mitigated substantially if reform is paired with enhanced energy-efficiency measures. Raising fuel and electricity prices reduces the payback period for products with higher efficiency, and helps raise public awareness of the links between efficiency and the cost of the energy they consume, but a push is typically required on the supply side to ensure that more efficient products are available on the market.

\subsection{Ensuring Adequate Investment for a Dynamic Upstream}

The ability to maintain oil and gas revenues at reasonable levels provides an important element of stability for the economy as a whole, especially when market conditions are tough. In this regard, though it may sound counter-intuitive in the narrative surrounding economic diversification, it remains crucial for producers to attract investment and maintain or improve the productivity of their upstream sectors. In a scenario where oil demand does not peak before 2040, all key producer economies will need to increase investment over the next decade just to maintain production levels close to those in 2017 (Fig. 4.6).

The need to step up investment comes at a time when there are many competing priorities for domestic spending, potentially limiting the capital available to national companies. The improving prospects of a range of new production areas mean there is also likely to be strong competition for international investment capital. The situation is, of course, 


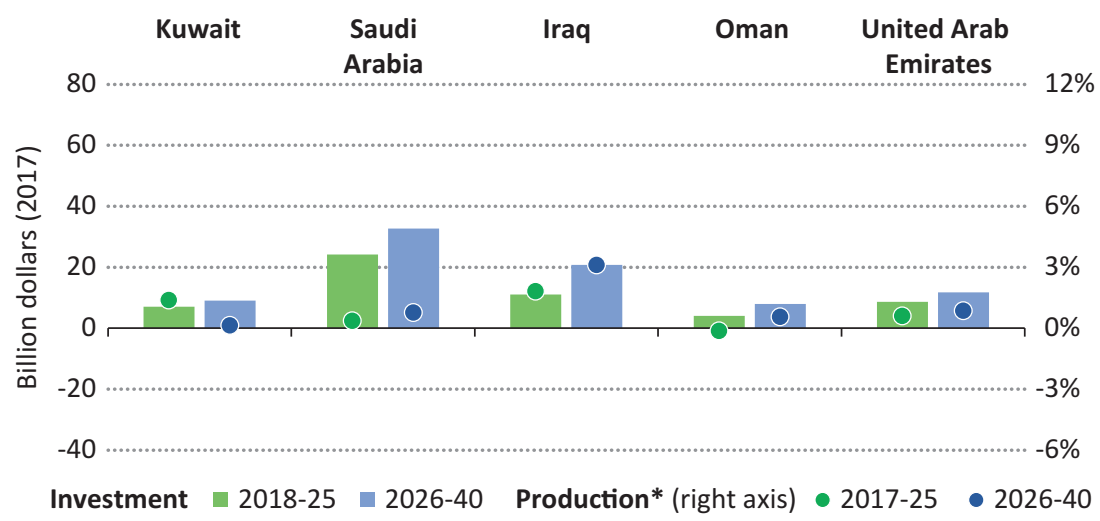

Fig. 4.6 Average annual upstream oil and natural gas investment and production in selected Middle East producers. (Source: International Energy Agency)

different across the producer economies, but it is clear that oil revenues will be crucial to national solvency well into the future, and will be a vital ingredient for any government wishing to reorientate the economy going forward.

Occupying the bottom end of the oil supply cost curve, Middle East producers could remain integral producers even in a Paris-compliant energy landscape where oil demand peaks imminently and falls to around $70 \mathrm{mb} / \mathrm{d}$ by 2040. Some producers, led by Saudi Arabia and the United Arab Emirates, have already shown that through intensified efforts to ensure elimination of gas flaring and methane leakages, they are also extremely competitive on a greenhouse gas emissions intensity basis, one factor that could differentiate suppliers of oil in the future.

\subsection{Supporting the Development of Cleaner and More Efficient Energy Technologies}

Many producers have world-leading expertise in energy technologies; in addition to their potential in renewables, they are also well positioned to develop new approaches that reduce or minimise the life cycle emissions of oil and gas.

Saudi Arabia and the UAE have made significant efforts to capture produced natural gas for either domestic use or export and so they flare and 
vent only very small volumes. This is also the case in Qatar and Kuwait. Despite the fact that the crude oil they produce is relatively sour, oil from these countries has among the lowest emission intensity of any source globally. Saudi Arabia and the UAE therefore point the way for other producer economies to step up their endeavours to eliminate flaring and venting.

There are a number of other options to reduce the GHG emissions intensity of oil and gas extraction. One possibility is to use solar energy rather than oil and gas to provide the energy needed to extract oil from the subsurface. This is particularly attractive in many Middle East countries, as they have high-capacity factors for solar PV and solar thermal plants. Although Saudi Arabia already has some of the least emission-intensive oil in the world, it is continuing to explore options to reduce this further.

Another possibility is to enhance oil recovery (EOR) using $\mathrm{CO}_{2} \cdot \mathrm{CO}_{2^{-}}$ EOR is one of the few options available today to monetise carbon capture, utilisation and storage (CCUS), since it can lead to higher levels of oil extraction while permanently keeping injected $\mathrm{CO}_{2}$ in the ground. There are important issues to be resolved-most notably ensuring that $\mathrm{CO}_{2}$ EOR leads to an overall reduction in the level of $\mathrm{CO}_{2}$ in the atmospherebut this represents an important opportunity for the producer economies to make a substantive contribution to the energy transitions. Not only could this help to reduce $\mathrm{CO}_{2}$ emissions directly, but as more capture, transport and $\mathrm{CO}_{2}$ storage facilities are deployed, it could help reduce the cost for future facilities, improving the economics of CCUS more generally. Saudi Arabia has expressed interest in these technologies and has a demonstration project that takes $\mathrm{CO}_{2}$ from a gas-processing plant for injection into the Uthmaniyah area of the super-giant Ghawar field.

Some producer economies are also considering possible alternative uses for oil and gas in the future which would minimise overall GHG emissions. One option is to increase the levels of hydrocarbons in noncombustion uses such as petrochemicals (discussed in the previous section). Another is to convert the hydrocarbons to a zero-carbon-vector such as hydrogen. This can be produced from methane using steam. If the $\mathrm{CO}_{2}$ from this process is stored underground, this zero-carbon hydrogen could help decarbonise a number of end-user sectors across the global energy system while still providing a mechanism to monetise the producer economies' hydrocarbon resources.

The economic argument for such measures becomes particularly compelling when synergies are found to couple industries in a mutually 
beneficial way. This is already happening, to some extent, for example, in the United Arab Emirates, where over 40 million standard cubic feet per day of carbon dioxide are being captured at the Al Reyadah steel plant before being piped to be used in enhanced oil recovery. This has the added benefit of freeing up the much-needed natural gas that would otherwise be used for the same purpose. Oman is pioneering the use of large concentrating solar projects for enhanced oil recovery, which could displace natural gas in providing the thermal energy needed in its oil production, thereby reducing the emission intensity of upstream production while at the same time freeing up increasingly scarce and valuable gas for domestic consumption or export.

\section{ImPliCATIONS AND CONCLUSIONS}

The objective to diversify hydrocarbon-dependent economies and reduce their reliance on oil and gas is not new, and the reform discussions unfolding in many countries today have many parallels with previous efforts. The longstanding nature of these efforts underscores that diversifying away from commodity dependency is genuinely challenging and raises a complex set of policy questions that do not have a straightforward solution.

Even in a relatively benign market and policy environment that assumes continued demand growth and relatively robust prices, the current economic model that recycles oil and gas incomes into jobs is unsustainable for some of the world's major producers. The challenges facing producer economies in the Sustainable Development Scenario are more profoundthe strong policy push for reductions in emissions, accompanied by rapid technological change, would imply persistent pressure on oil markets and consequently on the producers as well. Here, there is an inescapable imperative to prepare for a world in which hydrocarbons are no longer the main source of revenue, even if there may be alternative ways to monetise hydrocarbon resources that do not contribute to global emissions.

The starting conditions among even the Middle East's producers are very different, and risks are not evenly distributed. Collectively, however, these countries constitute an integral component of global supply, both in terms of how they can influence the future trajectory of the energy system and how they will be affected by it. In all scenarios, the Middle East's lowcost suppliers retain a significant share of global oil and gas supply.

Periods of higher prices caused by a supply crunch brought on by a period of under-investment may offer the possibility of temporary 
financial relief for producer economies, but they also present a clear downside. The imperative for reform has, in the past, subsided during periods of higher prices, and here too, they risk easing the pressures for change at just the time when higher prices accelerate the policy momentum behind alternatives to oil and gas, especially in some of the emerging global energy demand giants in Asia that are particularly sensitive to price swings. Higher prices would also have implications on the supply side, encouraging new, higher cost production in other parts of the world, and setting the stage for prices to fall again. Such volatility would be commensurately reflected in revenues, and in the absence of pro-cyclical fiscal policies in producer economies, can lead to diminished long-term economic growth.

A successful transformation of producer economies would have profound implications for the energy outlook. By reducing the "social costs" of production, that is, by diminishing the dependence on hydrocarbon revenues to finance areas such as education, health care and public sector employment, it would also lower the oil price at which these countries can manage without persistent fiscal deficits (Dale and Fattouh 2018). In such a case, oil markets could find an equilibrium at a lower price, with major low-cost producers taking a larger share of the market based on their position at the lower end of the global supply cost curve.

The implications of lower oil prices for energy transitions are more ambiguous. On the one hand, low prices could facilitate some policy shifts, such as introducing an effective or actual price on $\mathrm{CO}_{2}$ emissions. On the other hand, experience since 2014 has underlined that lower prices can provide a boost to global hydrocarbon consumption. Payback periods for many efficiency measures increase, and the growth of renewable technologies, outside the power sector, becomes much more challenging. The case for electric vehicle technologies would be particularly disadvantaged. To achieve the same outcomes, policies would need to be strengthened to counteract the effect of lower oil prices on transport and industrial demand.

This raises the question of the strategy that producer economies might follow in a lower demand scenario, and whether the prospect of accelerated energy transitions might invite producers to accelerate extraction of hydrocarbons (the so-called green paradox). The answer again is contingent upon the pace and extent of their broader economic transformation. If investments were to be mobilised to maximise production in such a case, this would bring down prices. Yet oil prices that cause producer economies to run into significant fiscal difficulties are unlikely to be maintained for long. 
Ultimately, in a world where demand for energy services is only going to increase, resource-rich countries will always seek value from their endowments, hydrocarbon or otherwise. The task ahead is to make this quest compatible with the gathering pace of change in global energy.

\section{REFERENCES}

Dale, S. and B. Fattouh (2018), Peak Oil Demand and Long-run Oil Prices, Oxford Institute for Energy Studies, Oxford, United Kingdom.

IEA (International Energy Agency) (2018), Outlook for Producer Economies, OECD/IEA, Paris.

Open Access This chapter is licensed under the terms of the Creative Commons Attribution-NonCommercial-NoDerivatives 4.0 International License (http:// creativecommons.org/licenses/by-nc-nd/4.0/), which permits any noncommercial use, sharing, distribution and reproduction in any medium or format, as long as you give appropriate credit to the original author(s) and the source, provide a link to the Creative Commons license and indicate if you modified the licensed material. You do not have permission under this licence to share adapted material derived from this chapter or parts of it.

The images or other third party material in this chapter are included in the chapter's Creative Commons licence, unless indicated otherwise in a credit line to the material. If material is not included in the chapter's Creative Commons licence and your intended use is not permitted by statutory regulation or exceeds the permitted use, you will need to obtain permission directly from the copyright holder. 